\title{
SUSTENTABILIDADE NO FOCO DA INOVAÇÃO
}

\section{SUSTAINABILITY FOCUS ON INNOVATION}

\author{
Silvia Mara Bortoloto Damasceno ${ }^{1 ;}$ Danielly Silva de Aquino²; Patrício Henrique Vasconcelos ${ }^{3}$; \\ Dálcio Roberto dos Reis ${ }^{4}$; Alexandre Dias Barcelos ${ }^{5}$ \\ ${ }^{1}$ Universidade Tecnológica Federal do Paraná - UTFPR - Ponta Grossa - Brasil \\ smbdamasceno@uem.br \\ ${ }^{2}$ Universidade Tecnológica Federal do Paraná - UTFPR - Ponta Grossa - Brasil \\ dsaquino@uem.br \\ ${ }^{3}$ Universidade Tecnológica Federal do Paraná - UTFPR - Ponta Grossa - Brasil \\ adm.patricio@yahoo.com.br \\ ${ }^{4}$ Universidade Tecnológica Federal do Paraná - UTFPR - Curitiba - Brasil \\ dalcio@utfpr.edu.br \\ ${ }^{5}$ Faculdade Tecnológica Paranaense - FATEP - Cianorte - Brasil \\ 7barcelos@gmail.com
}

\section{Resumo}

A inovação tecnológica é cada vez mais relevante para que as organizações obtenham sucesso e diferencial competitivo. No entanto, as inovações vêm desenvolvendo tecnologias focadas em sustentabilidade, de modo a alcançar equilíbrio entre o ambiental, o social e o econômico. $O$ objetivo deste trabalho é discutir a interface entre sustentabilidade e a inovação. Para isso foi realizado estudo em materiais já publicados, tais como, dissertação, periódicos e bibliografias que discorrem sobre sustentabilidade, inovação tecnológica e a interface entre ambas. Observa-se que a vantagem das organizações desenvolverem e lançarem novos serviços, produtos, processos $e$ negócios detentores das modificações inovadoras, com abrangência ambiental, social e econômica, proporciona vantagem competitiva, no qual organizações inovadoras e sustentáveis ganham espaço param se tornarem líderes de mercado. Considerando a operacionalização do sistema produtivo aliado as inovações que vislumbram atender as dimensões da sustentabilidade, que buscam atingir resultados ao mínimo eficientes ao meio ambiente, como a redução de uso de seus recursos naturais não renováveis, emissões causadoras de poluição, dentre outros, assim, o aumento produtivo com a demanda de produtos novos pode incorrer na neutralização ou ainda na superação de simplesmente bons resultados. Agregando-se o possível tratamento adequado ao maior desafio para que as empresas se alinhem a um padrão organizacional inovador sustentável.

Palavras-chaves: Inovação, Sustentabilidade, Interface.

\section{Introdução}

O mundo está passando por um processo de mudanças. As relações econômicas, as inovações tecnológicas e os valores da sociedade provocaram alterações na estrutura e no ambiente organizacional. Grayson (2002) defende que as forças globais destas mudanças surgiram com a revolução tecnológica, com a revolução dos mercados, com a revolução na demografia e no 
desenvolvimento, e principalmente com a revolução dos valores.

Esta última revolução baseada em ideias e percepções colaboraram para existência das mudanças na natureza dos negócios, no comportamento das pessoas, no papel do Estado e cada vez mais impacta o modo de vida das populações e no comportamento das organizações empresariais.

Diversos agentes sociais já perceberam que a intervenção excessiva do homem e das empresas no planeta compromete diretamente a existência de recursos naturais e a possibilidade de sobrevivência de sistemas sociais, ambientais e econômicos num futuro próximo.

Desta forma, o desenvolvimento e a sustentabilidade se unem numa expressão de ideologias que visam a evolução com o prisma ambiental de forma inesgotável, visando garantir o que há por vir com planejamentos e consciência aplicados de forma consistente, em quaisquer dos âmbitos do negócio sócio-econômico empresarial e comercial, unidos pelo real e substancial compromisso.

A sustentabilidade desenvolvida tem sua tradução no alcance do padrão desejado, incutido na sociedade especificamente em seu estilo de vida, cujos recursos da natureza compõem o foco de condicionamento para o futuro, isto é, aceitando a imposição calada que a natureza exige.

Assim, o impacto causado consiste num fato a ser aceito e enfrentado como um problema a ser assumido pela responsabilidade de todos sem exceção, localizada a sustentabilidade na relação sócio-ambiental de todo e qualquer indivíduo. $\mathrm{O}$ desenvolvimento tem em si inserido atender o presente sem condenar o futuro, ou mesmo as possibilidades para as gerações vindouras.

A inovação traz em si a tendência de combate ao impacto na natureza, defendendo o desenvolvimento tecnológico sem o abalo na natureza, com o fim de conservá-la para a descendência. Consistindo numa consciência centralizada de estratégia que traz a maximização na questão da sustentabilidade com ecoeficiência aplicada.

A proposta entre desenvolvimento e sustentabilidade é fundamentada nos recursos naturais renováveis que resultem em renovação pelo emprego da otimização adequada aos elementos naturais do eco-sistema, visando a manutenção ambiental pela aplicação conscientizada no âmbito sócio-econômico empresarial que pretende incutir a inovação tecnológica num determinado grau evolutivo que atinja de maneira competentemente estabelecida a sustentabilidade junto ao meio ambiente.

Dentro deste contexto o objetivo deste trabalho é discutir a interface entre sustentabilidade e inovação. Para isso foi realizado estudo em materiais já publicados, tais como, dissertação, periódicos e bibliografias que discorrem sobre sustentabilidade, inovação tecnológica e a interface entre ambas.

\section{Sustentabilidade: equilíbrio ambiental, social e econômico}

Sustentabilidade consiste no entendimento idealizado pelo homem como um evento social 
com amplitude filosófica, inserido num plano social de vida futura. No entanto existem contrariedades (KEINERT, 2007).

Para Bellen (2004, p.73) "sustentabilidade requer um padrão de vida dentro dos limites impostos pela natureza".

Corroborando Fialho et al. (2008) diz que sustentabilidade e desenvolvimento interligamse na expressão ideológica daquilo que possui continuação de tempo para tempo. A sustentabilidade traz idéia do que é perene, isto é, inesgotável, de algo que existe na atualidade e garantidor do futuro, ligado a questão ambiental, preocupação com fontes dos recursos naturais, degradabilidade do meio ambiente além do compromisso como processo socioeconômico.

A definição de desenvolvimento é trazida dentro da capacidade de atender as necessidades do presente, sem comprometer as gerações futuras. Onde os autores definem "desenvolvimento sustentável é aquele que atende às necessidades do presente sem comprometer a possibilidade de as gerações futuras atenderem às suas próprias necessidades” (FIALHO et al. 2008, p.40).

De acordo com Manzini e Vezzoli (2005), o trabalho humano de modo algum deveria impactar os ciclos naturais propostos pela natureza, nem mesmo sequer abalar o capital natural que pertencerá para as gerações futuras. Portanto, Manzini e Vezzoli (2005) afirmam que o tema conhecido como desenvolvimento sustentável parte buscando ênfase em atingir consciência dentro de uma centralização estratégica que envolve e maximiza a sustentabilidade.

Pontos chaves, tais como a variedade, complexidade, entre outros, são questões que demonstram a determinação pela aproximação perseguida em torno da sustentabilidade, que tende em promover articulação consistente numa diversidade de planos em que haja intervenção de cada setor social.

As vantagens competitivas sustentáveis dependem de como a empresa percebe as necessidades dos clientes e quais as ações da empresa para atendê-los, pois necessita superar a percepção dos concorrentes (FIALHO et al., 2008).

Percebe-se, portanto, que a sustentabilidade depende da adoção de várias práticas e do nível que estas práticas afetam o desenvolvimento. Envolvem dilemas, que se esbarram no consumo consciente, conflitos de interesses, ética e legalidade, que precisam ser mensurados.

A sustentabilidade não pode ser entendida apenas como uma sensibilização as questões do meio ambiente, mas sim como uma forma de reflexão e ação de caráter duradouro que alinha com as questões sociais e econômicas.

Sob o ponto de vista empresarial podemos compreender esta relação pelo pensamento de Hart (2006) quando afirma que assim como as empresas precisam ser bem sucedidas em várias frentes para criar valor para os acionistas, devem também superar os desafios econômicos, sociais e ambientais para atingir a sua sustentabilidade. 
Assim, neste campo dinâmico, complexo e com significados diversos, insere-se a sustentabilidade nas empresas, despontando como um vetor estratégico e necessário para se garantir a sobrevivência do sistema organizacional e, principalmente o ambiental de modo sustentável.

Desta forma, no longo prazo, as organizações deverão buscar construir a sua sustentabilidade amparada no tripé dos aspectos econômicos, sociais e ambientais, denominados de Triplo Botton Line, conceito difundido por Elkington (1997) de modo a dar operacionalidade aos aspectos da sustentabilidade nas organizações, de modo que se este tripé não for igualmente válido, não há a sustentabilidade.

De acordo com o autor a destruição do meio ambiente está diretamente ligada à maneira como as pessoas optaram por realizar o desenvolvimento a partir da Revolução Industrial. Desde então, o setor industrial exigiu que o homem retirasse da natureza os recursos indispensáveis para o aumento da economia social.

A idéia de se manter sustentável segundo Rocha Loures (2009) emprega um novo modelo social com condições que garanta a sobrevivência.

Sobre isso Kotler (2007) sugere que as organizações pratiquem a sustentabilidade, pois, o julgamento do consumidor a respeito do desempenho empresarial considera a utilização com eficiência da matéria-prima no processo de produção. Serão criticadas também as indústrias e o meio empresarial que vier a desperdiçar e poluir quimicamente o meio ambiente, de acordo com o autor.

Considera-se a sustentabilidade uma idéia cheia de iniciativas que envolve um sistema de mudança. Explanando melhor sobre o assunto, Sachs (1997) apud Strobel (2005), diz que devem ser consideradas cinco principais dimensões: econômica, social, ambiental, geográfica/espacial e ecológica. Para o autor, a dimensão política está inserida na dimensão social. Strobel (2005) diz ainda que a interpretação de Sachs é a mais conhecida, porém o número de dimensões da sustentabilidade varia de acordo com o ponto de vista de cada autor.

Entretanto, considerada-se aqui, de forma mais abrangente, o conceito de sustentabilidade na qual Sachs (1997) apud Strobel (2005) propõe uma visão tridimensional de ordem social, ambiental e econômica, sendo utilizado na maioria dos contextos de indicadores de sustentabilidade.

As dimensões conforme Strobel (2005):

\section{a) Social}

A sustentabilidade observada na esfera social enfatiza a presença do ser humano na ecosfera, sendo que a preocupação principal desta linha é com o bem-estar humano e a qualidade de vida (...)

b) Econômica

(...) é possibilitada por uma alocação e gestão mais eficiente dos recursos e por um fluxo regular do investimento público e privado. (...) a eficiência econômica deve ser avaliada 
mais em termos macro-sociais do que apenas por critérios de lucratividade microempresariais. Assim, considera-se o impacto do fluxo monetário existente entre empresas, governo e população.

\section{c) Ambiental}

(...) a principal preocupação é relativa aos impactos das atividades humanas sobre o meio ambiente. (...) Deve-se reduzir a utilização de combustíveis fósseis e a emissão de substâncias poluentes, adotar políticas de conservação de energia e recursos naturais, substituir produtos não-renováveis por renováveis e aumentar a eficiência dos recursos utilizados (STROBEL, 2005, p.16-17).

Neste contexto a sustentabilidade só será atingida se sociedade, empresa e governo, atenderem aos critérios das três dimensões impreterivelmente.

\section{Inovação tecnológica}

A inovação combina necessidade social e demanda com proposta tecnológica e científica, transformando produto, processo e serviço para o mercado. Assim inovação envolve funções novas com a evolução que altera métodos de produção, desenvolvendo uma organização de trabalho contemporânea que produz novas mercadorias, abrindo campo para consumos e criação de usos (CARON, 2006).

Para Reis (2004) tecnologia é o conjunto de conhecimentos científicos ou empíricos diretamente aplicáveis à produção ou melhoria de bens ou serviços. Segundo esse conceito a ligação entre ciência, tecnologia e inovação destaca o impacto socioeconômico na comunidade sendo aplicados conceitos materiais sobre processo de fabricação, inclusive métodos e produtos no meio de produção.

O autor diz ainda que a tecnologia se classifica em materializada, documentada ou imaterial. A primeira corresponde ao equipamento do processo produtivo como produto final de um certo conjunto, exemplificando, preço, design, softwares, entre outros. A outra espécie, documentada existe pela própria documentação, aos quais se descreve e se explica as soluções, isto é, plantas, livros técnicos, manuais, dentre outros. $\mathrm{O}$ aspecto imaterial tecnológico tem sua referência no conhecimento teórico e prático, imprescindível para produção e utilização de bens e serviços. Essa tecnologia se adquire formando o exercício aplicado ao conhecimento.

Em termos industriais a tecnologia se define como conhecimento tecnocientífico que se organiza e sistematiza a atividade industrial. Dentro do processo tecnológico de inovação o agente protagonista pela alteração da atualidade é a inovação tecnológica, que se define tecnicamente como uma idéia que desenvolve um momento prático provocando o sucesso (REIS, 2004).

Outra definição aplica-se ao conhecimento tecnológico que traz o produto novo ou serviços e processos, sempre melhorando os próprios atributos. Essa inovação envolve o plano científico juntamente com o teórico, essa inovação provoca mudança prévia pelo próprio conceito baseado na tecnologia da empresa. O procedimento que inova consiste na capacidade de tecnologia e da 
necessidade mercantil no contexto empresarial e inovador, competindo e globalizando mercados como fator que sobrevive a organização (REIS, 2004).

Nesse contexto, o conhecimento apropriado que gera inovação e uma tecnologia moderna capaz de desenvolver e transformar ideias é indispensável, pois, a rentabilidade para as empresas que nascem vem pela criatividade empreendida com visão no futuro (CARON, 2006).

Segundo Reis (2004) o recurso humano é fundamental para o acúmulo de conhecimento e para construção de capacidade tecnológica empresarial, originando nesse ponto a competitividade. Nesse elemento pode estar o diferencial inovador que determina o processo da organização envolvendo o mercado, justificando-se a qualificação pessoal do profissional que se contrata.

Na concepção de Gibson e Skarzynski (2008) quando a empresa assume inovar atinge um momento determinante. Percebe-se que inovar não depende apenas de corporativismo ou pontualidade, reconhecem que inovar envolve valores, comportamento, sistemas de gestão, estrutura organizacional dentre outros, e de fato entende que a inovação funciona se for sustentável de vendo ser sistêmica e ampla em sua capacidade.

$\mathrm{Na}$ concepção dos autores supra citados, inovar se torna para a empresa um estilo de vida, no entanto, a maioria dessas organizações empresariais não alcança o objetivo, a fragmentação de soluções não é suficiente, isto é, o ponto crucial só é atingido quando há uma meta sistêmica que incorpora a inovação da empresa como o DNA organizacional. A aplicação da sustentabilidade junto da inovação na empresa depende do estilo a ser seguido pelo cotidiano mercantil da mesma, cujos aspectos necessários quando seguidos de forma compromissada torna essa empresa mais forte e competitiva, tecnologicamente falando.

Segundo os autores o desejo pela inovação deve ser uma prioridade profunda e fundamental que a organização assuma por sua atividade aliada a qualidade criando assim o aumento dessa capacidade empresarial, em que essa difícil batalha gerencial traz a aptidão sólida e sustentável quando o desafio é vencido incorporando a instituição junto da inovação tecnológica e consequentemente atingindo o nível internacional.

Conforme expõem Gibson e skarzynski (2008) é dever da organização reconhecer tal prática inovadora, bem como, normas e procedimentos internos que prejudiquem a inovação, como gerências excessivamente tradicionais que perpetuem essa sistemática e o incremento frente a pensamentos e idéias novas e inovadoras.

Dessa forma os autores afirmam que é preciso calcular que a empresa criada voltada para a inovação não se trata tão somente de exigir das pessoas essa inovação, mas sim de assumir concretamente o desafio de alterar os aspectos que diminuem ou atrasam a potência inovadora dessa empresa.

Em termos práticos, uma empresa sustentável, segundo Scharf (2004), seria aquela que 
consegue manter sua viabilidade econômica num médio e longo prazo, opera dentro da lei, minimiza dependência de recursos esgotáveis e impactos sobre recursos naturais, desenvolve produtos e serviços para o que é percebível como um benefício social ou ambiental, estabelece uma relação de respeito com o seu grupo de stakeholders, sendo transparentes, envolvidas com questões de ordem globais como o aquecimento global.

Portanto, uma forma efetiva das empresas colaborarem com o desenvolvimento sustentável do planeta e sua própria competitividade é a modificação de seu processo produtivo para que se tornem sustentáveis. Ainda sobre esta ótica, Hart (2006) expõe que reconhecer a sustentabilidade com um catalisador para o desenvolvimento de novos negócios será cada vez mais importante para sobrevivência corporativa no século XXI.

Pelo exposto, podemos entender que as organizações deverão estabelecer e perseguir como objetivos e metas, a realização de uma produção mais limpa, respeitar os direitos humanos, atuar com valores éticos e respeitar os limites dos recursos não renováveis.

\section{A interface entre a sustentabilidade e a inovação}

O desequilíbrio mundial atrelado a ação dos governos, somado com o padrão sócio cultural exige soluções e não perguntas sem respostas ou meras justificativas. No pensamento de estratégia especializada de natureza econômica para atingir a sustentabilidade um alto nível de inovação é sem dúvida a certeza ambiental, para tanto, a mobilização governamental, organizacional, empresarial e pessoal é imprescindível. Assim a resposta para um problema de sustentabilidade está em inovar, envolvendo a economia, a sociedade e contando com o meio ambiente para idéias, métodos, procedimentos e comportamentos avançados ao tempo, conforme expõe (PAULA, 2009).

Dentro do agendamento da inovação a preocupação com sustentabilidade é de considerável relevância, que se encontram numa gama de fatores, cujos mais comuns pode-se citar aqueles que geram mudanças climáticas, como o aquecimento global; aqueles que geram orientação ecológica por meio de pressão em produtos e serviços como a poluição ambiental; pelos problemas de concentração de massa urbana por causa do aumento e da distribuição de população; pela emergente preocupação com o descobrimento de fontes alternativas de renovação, diminuindo-se as fontes esgotáveis de recursos; inclui-se o fator que relaciona os padrões básicos, como a água tratada, medidas de soluções sanitárias envolvendo a saúde, dentre outros (TIDD; BESSANT; PAVITT, 2008).

A sustentabilidade negocial relacionada com o desenvolvimento sustentável sendo compreendida como alavanca de efetividade é avaliada com requisitos inovadores, assim justificase esse estudo como cerne da sustentabilidade a desenvolver de natureza conceitual. Nesse seguimento o conceito sustentável e inovação devem resultar num fim social, econômico e 
ambiental positivo, compreendendo que tal disposição é como uma arte que envolve inovações radicais com novidade de alto grau. Essa proposição avança uma intenção de qualidade, pois não se trata apenas de aplicar uma boa ideia, mas sim, de gerar uma evolução de elevada importância a nível populacional, isto é, formar uma opinião apoiadora da sustentabilidade que se desenvolve com aplicação de alterações sociais envolvendo uma mudança técnica entre os padrões da sociedade (SCHOT; GEELS, 2008 apud BARBIERI et al., 2010).

Segundo o Manual de Oslo, inovação "é a implementação de um produto (bem ou serviço) novo ou significativamente melhorado, ou um processo, ou um novo método de marketing, ou um novo método organizacional nas práticas de negócios, na organização do local de trabalho ou nas relações externas" (OECD, 1997, p. 55).

Considerando a posição de Kemp e Pearson (2008) que definem o termo próprio de ecoinovação como a exploração do produto, o processo, o serviço ou o método que gere o negócio que traz a novidade organizacional, que com a evolução do ciclo diminui poluição, impactos nos recursos naturais e o risco ambiental no desenvolvimento adotado.

Outro ponto que envolve a inovação frente a sustentabilidade consiste na avaliação socioambiental inserida no processo inovador e não somente na avaliação de natureza econômica, considerando que gerir inovação demonstra resultados negativos ou inesperados que podem redirecionar ou interromper um determinado procedimento inovador, esse bloqueio pode ocorrer no projeto cujo resultado social e ambiental também pode ser negativo (BARBIERI, 2007).

O foco inovador no grupo conhecido como stakeholders (clientes, fornecedores, investidores e órgãos reguladores) frente a consideração do impacto gerado detém um interesse secundário pela sociedade ou mesmo ambientalistas que se posicionam contra a globalização dentre outros interesses de esquerda. Esse interesse secundário é restrito ao entorno da operação organizacional, afetando a inovação, logo esse motivo leva a tendência da evolução da responsabilidade social de empresas que superem desafio através de movimentos que divulguem propostas transparentes sobre suas ações e resultados de impacto social, econômico e ambiental que provocam (HALL; VREDENBURG, 2003 apud BARBIERI et al., (2010).

No seguimento da dimensão de sustentabilidade, a inovação não corresponde a um padrão, pois, as dimensões ambiental e social, exigem instrumentos modernos de aplicação que a pouco tempo são empreendidos com intensidade. Nesse raciocínio as instituições, organizações e órgãos do governo desenvolvem um papel importante. A incorporação efetiva na sustentabilidade incorpora a inovação desenvolvida que adequadamente mobilizada transforma a realidade, mais precisamente entre as empresas quatro questões determinam o desenvolvimento inovador que garante a incorporação da sustentabilidade almejada, quais sejam, certificar-se que a sustentabilidade estará incutida no processo de criação e no processo de gestão da empresa; como e 
quando a visão externa estará no processo criativo de desenvolvimento da inovação e quais processos têm maior relevância para o aumento do valor do capital intelectual da organização (DORMANN; HOLLIDAY, 2002).

Enfim relevante ressaltar a facilidade abordada que se pretende introduzir e difundir na sustentabilidade através das tecnologias inovadoras permitindo que a evolução prática alcance o uso estrutural. Setores como da energia, de transporte público e de alimentos ecológicos comporiam esse quadro abordado, pois, essa ação basilar constrói o meio adequado de natureza social e ambiental que contribui efetivamente para a transformação que atinge o desenvolvimento sustentável através da implantação de um serviço ou produto que seja inserido de forma efetiva no mercado de consumo.

"Insanidade é continuar fazendo sempre a mesma coisa e esperar resultados diferentes" Albert Einstein.

\section{Sustentabilidade e inovação: aspectos em discussão}

$\mathrm{Na}$ atual conjuntura pesquisada deve-se considerar a preponderância relacionada entre ciência e tecnologia, em que a tecnologia se desvincula do impacto em tela e não agrega a preocupação de natureza econômica ou o bem estar social. Esse vínculo tecnológico vem unido ao processo e produtos sendo existente o cabimento da patente.

No seguimento dados pelos autores supra citados o conhecimento social vem definido segundo o termo tecnológico como uma arte industrial, constituindo um fundamento na elaboração do conhecimento e do método científico, cujo domínio material procede da utilidade na aplicação da solução de problemas dentro da natureza técnica para fabricar o novo produto, com conceito de aplicabilidade da inovação voltado para a sustentabilidade a que se destina.

Para tanto, a tecnologia capacitada tem sua etapa de produção com o nível em que a mesma é desenvolvida com o foco no conhecimento intangível, ou seja, a aquisição de uma ferramenta com apoio no desenvolvimento de um produto essencial que componha esse avanço tecnológico.

No entendimento de Reis (2004) a inovação tecnológica em empresas se define por meio da experiência e domínio no procedimento inovador. Dessa forma a modificação traz a adaptação para a tecnologia que também tem aliança com o conhecimento aprimorado, incurso na introdução dos novos produtos, serviços ou processos como fundamental elementos imateriais que auxiliam na formação da tecnologia inovadora.

Um elemento preponderante que está situado junto a competitividade que se aloja na força detida pela empresa que identifica as mudanças comerciais e as interpreta acertadamente junto das mais variadas preferências. Esse ponto também provoca a inovação na visão científica, sendo que o conhecimento assim aplicado também inova, seguindo as tendências que a teoria vertente executa. 
A criação de novas oportunidades desafia a existência em uso, cujo potencial sustentável dá margem a mercados com fontes de alternatividade ecológica para energia, produtos e serviços. Implica à inovação sustentável de natureza tecnológica na ênfase de compatibilidade com o contexto cultural, político e social, esses muito complexos e oferecedores de um grande risco para o fracasso se a demanda for negligente.

$\mathrm{O}$ exame da natureza e a função das redes inovadoras são limitadas quando focam em específico o produto ou a tecnologia, o que se torna inadequado para o avanço. Em contra partida a análise deve envolver sistemas tecnológicos evoluídos em sua gestão, compatibilizando a influência do sistema inovador e a trajetória da função tecnológica. Inovar tecnologicamente deve combinar demanda de mercado com as expectativas e preocupações sociais o que seria ideal para aplicação.

Assim corresponde, segundo várias opiniões, na quebra de paradigmas comerciais e negociais, a inovação, que avança na busca do alcance do sucesso, face as mais precisas avaliações como trajetória mercantil.

O risco trazido deve ter o enfrentamento com extrema consciência pela vez que se projeta o lançamento para a competição em mercado junto das demais empresas que almejam atingir a maior lucratividade ou o básico êxito próprio, na concepção de (REIS, 2004).

Como cita Caco de Paula (2009), segundo um pensamento de Einstein ele dizia que insanidade é continuar fazendo sempre a mesma coisa e esperar resultados diferentes. Isso corresponde a atitude acompanhada da máxima sanidade para a aplicação e combate aos desafios que as relações pessoais ocasionam, pois, esse detalhe é vívido quando se trata de pessoas aos pontos de educação, trabalho, negócios, renovação constante, dentre outros.

Com supedâneo no Manuel de Oslo, a inovação tem sua inserção na implementação do bem ou do serviço que um produto novo exige para seu lançamento mercantil e negocial, trazendo ao mesmo o acompanhamento de melhorias nos processo ou no procedimento metodológico que envolve negócio e organização empresarial.

Um ponto levantado durante esse estudo preconiza a 'ecoinovação' junto da inovação com a produção, exploração e assimilação de um serviço ou produto ou processo de produção que seja gerido ou negociado como 'novo'. Todavia, esse desenvolvimento e essa nova adaptação devem trazer resultados de longevidade no próprio ciclo existencial, ou seja, que alcance redução no risco ambiental, eliminação da poluição e de impactos negativos nos ambiente natural, numa comparação alternativa pertinente a proposta.

Na idéia de Kemp e Pearson, (2008) tudo isso é devido aos impactos negativos que geralmente vem logo em seguida de uma proposta de inovação, como emissão de poluentes, escassez e esgotamento de recursos naturais, enfatizando uma redução de todos os problemas causados, primando por evitá-los definitivamente, como pressuposto benéfico econômico-social e 
científico-tecnológico, que se reflete de alguma forma.

Logo, questões como a oferta de ecoeficiência, devidamente aplicada reduz a quantia de energia e matéria por unidade produzida, eliminando assim substâncias tóxicas e trazendo o aumento da vida útil de um produto. Em contrapartida, há uma corrente que pende na preocupação com o desemprego, a destruição de competência, um eventual prejuízo à comunidade ou até mesmo a alguns segmentos sociais, entre outros possíveis problemas. Nessa dimensão se assenta a proposta da inovação 'ecoeficiente’ para a inovação voltada para a sustentabilidade.

Afere-se ao final que a ação descuidada, sem inovação tecnológica ou mesmo falhas no avanço do aprimoramento do conhecimento ocasionam uma ação humana que de fato afeta o meio ambiente em que se vive, e de pronto, a preocupação é contínua e perene objeto a que se volta o aspecto evolutivo, numa constante busca de evitar o impacto ambiental.

Esse foco é diretriz de muito planejamento e pesquisa tecnológica que prepondera para aplicar execuções inovadoras, para que não venham a ocorrer prejuízos o que é naturalmente ambiental, numa proposição de sustentabilidade ou mesmo de inovação sustentável.

\section{Considerações finais}

A inovação sustentável se configura através da organização institucional, que desenvolve sua aplicação com eficiência considerando os aspectos naturais agregados a responsabilidade sócioambiental.

A vantagem dessa aplicação reflete na concorrência comercial em que a competitividade se aloja no lançamento de novos serviços, produtos, processos e negócios detentores das modificações inovadoras, com abrangência ambiental, social e econômica.

Estando reunidas tais características, se provoca o que é essencial para a inovação sustentável, ou seja, a orientação para a sustentabilidade com objetivos planejadamente alcançáveis como previsão nascida na institucionalização de uma nova lógica produtiva, sob a qual o fenômeno da sustentabilidade e da inovação sustentável andam de mãos dadas.

Considerando esse isomorfismo na instituição, ou seja, a concentração de organização de suas várias formas em seus setores de produção, almejar esse padrão de uma organização inovadora e sustentável, ganha dia a dia mais espaços frente as ditas empresas que são líderes de mercado.

Logo, se permite afirmar que a movimentação mais relevante é o julgamento da vitalidade de fatores sustentáveis inseridos nessas instituições que não fazem parte de muitos planos a serem executados pelo mundo todo, pois, o êxito disso tudo pode inferir na sua propagação por muitos anos a fim.

Finalmente, aprimorar esses moldes organizacionais sustentáveis, com as mais variadas formas de as institucionalizar globalizadamente falando, traz o desenvolvimento sustentável, capaz 
de relevantes estudos para o futuro, dentro do aspecto que é objeto de negligência para o padrão de uma organização sustentável referida ao consumo de novos e inovadores bens, serviços ou produtos.

Considerando afinal a operacionalização do sistema produtivo aliado as inovações que visem atender as dimensões da sustentabilidade, que visem resultados ao mínimo eficientes ao meio ambiente, como a redução de uso de seus recursos naturais não renováveis, emissões causadoras de poluição, dentre outros, assim, o aumento produtivo com a demanda de produtos novos pode incorrer na neutralização ou ainda na superação de simplesmente bons resultados. Agregando-se o possível tratamento adequado ao maior desafio para que as empresas se alinhem a um padrão organizacional inovador sustentável.

\begin{abstract}
Technological innovation is increasingly important for organizations to achieve success and competitive advantage. However, innovations are developing technologies focused on sustainability in order to achieve balance between environmental, social and economic issues. The aim of this paper is to discuss the interface between sustainability and innovation. For this study was conducted on material already published, such as paper, journals, and bibliographies that talk about sustainability, technological innovation and the interface between them. It is observed that the advantage of organizations to develop and launch new services, products, processes and business owners the innovative changes, to reach environmental, social and economic, provides competitive advantage, in which innovative and sustainable organizations are gaining ground stops become market leaders. Considering the operation of the production system together with the innovations that meet envision the dimensions of sustainability, seeking to reach the minimum efficient outcomes for the environment, such as reducing use of nonrenewable natural resources, pollutioncausing emissions, among others, so increased production with demand for new products may incur in the neutralization or simply to overcome good results. Taken together, the appropriate treatment can be the greatest challenge for companies line up to a sustainable innovative organizational pattern.
\end{abstract}

Key-words: innovation, sustainability; interface.

\title{
Agradecimento
}

Agradecemos a Fundação Araucária pelo apoio financeiro.

\section{Referências}

BARBIERI, J. C. Organizações inovadoras sustentáveis. In: BARBIERI, J. C; SIMANTOB, M. Organizações inovadoras sustentáveis: uma reflexão sobre o futuro das organizações. São Paulo, Atlas, 2007.

BELLEN, H. M. V. Desenvolvimento sustentável: uma descrição das principais ferramentas de avaliação. Revista Ambiente e Sociedade, Campinas/SP, v. 7, n. 1, p.67-88, jan./jun. 2004.

CARON, A. Inovação tecnológica e a pequena e média empresa local. In: O desenvolvimento sustentável em foco: uma construção multidisciplinar. Gilson Batista de Oliveira, José Edmilson de Souza-Lima (Org.). Curitiba: São Paulo: Annablume, 2006. 
DORMANN, J.; HOLLIDAY, C. Innovation, technology, sustainability and society. World Business Council for Sustainable Development. July 2002. Disponível em: <http://www.bvsde.paho.org/bvsacd/cd30/society.pdf>. Acesso em: 22 nov. 2010.

FIALHO, F. A. et al. Gestão da sustentabilidade na era do conhecimento. Florianópolis: Visual Books, 2008.

GIBSON, R.; SKARZYNSKI, P. Inovação: prioridade $n^{\circ}$ 1: o caminho para transformação nas organizações. Tradução de Alessandra Mussi Araujo. Rio de Janeiro: Elsevier, 2008.

GRAYSON, D; HODGES, A. Compromisso social e gestão empresarial. Tradução Carlos Mendes Rosa et al. São Paulo: Publifolha, 2002.

HALL, J.; VREDENBURG, H. The challenges of innovating for sustainable development. Sloan Management Review, v. 45, n.1, p. 61-68, 2003. In: BARBIERI, José Carlos et al. Inovação e sustentabilidade: novos modelos e pro posições. RAE, São Paulo, v.50, n.2, p.146-154, 2010.

HART, S. L. O capitalismo na encruzilhada: as inúmeras oportunidades de negócios na solução dos problemas mais difíceis do mundo. Tradução: Luciana de Oliveira Rocha. Porto Alegre: Bookman, 2006.

KEMP, R.; PEARSON, P. (Eds) Final report of the project Measuring Eco-Innovation. Maastricht (The Netherlands). 2008, 113 p. Disponível em: 〈http://www.merit.unu.edu/MEI/index.php〉. Acesso em: 22 nov. 2010.

KEINERT, T. M. M. Organizações sustentáveis: utopias e inovações. São Paulo: Annablume; Belo Horizonte; Fapemig, 2007.

KOTLER, P. Inovação, Fidelidade, Segmentação, Sustentabilidade e Customização. 2007. Disponível em: <http://www.scribd.com/doc/232261/Philip-Kotler-fala-sobre-inovacao-fidelidade-segmentacao-sustentabilidade-ecustomizacao>. Acesso em: 13 out. 2010.

MANZINI, E.; VEZZOLI, E. O desenvolvimento de produtos sustentáveis. Tradução de Astrid de Carvalho. I ed reimpr. São Paulo: Editora da Universidade de São Paulo, 2005.

OECD. Manual de Oslo: diretrizes para coleta e interpretação de dados sobre inovação. Tradução FINEP, 1997.

PAULA, Caco de. Sustentabilidade exige ideias novas. 2009. Disponível em:

<http://planetasustentavel.abril.com.br/especiais/sustentabilidadeinovacao/>. 14 out. 2010.

REIS, D. R. Gestão da inovação tecnológica. São Paulo: Manole, 2004.

ROCHA LOURES, R. C. Sustentabilidade XXI: educar e inovar sob uma nova consciência. São Paulo: Editora Gente, 2009.

SCHARF, R. Manual de negócios sustentáveis. São Paulo: Amigos da Terra; FGV; GVces, 2004.

SCHOT, J; GEELS, F. W. Strategic niche management and sustainable innovation journeys: theory, findings, research agenda and policy. Technology Analysis \& Strategic Management, v. 20, n. 5, p. 537-554, 2008. In: BARBIERI, José Carlos et al. Inovação e sustentabilidade: novos modelos e pro posições. RAE, São Paulo, v. 50, n. 2, p. 146-154, 2010

STROBEL, J. S. Modelo para mensuração da sustentabilidade corporativa através de indicadores. 2005. $136 f$. Dissertação (Mestrado em Engenharia de Produção) - Curso de Pós-Graduação em Engenharia de Produção, Universidade Federal de Santa Catarina, Florianópolis, Brasil, 2005.

TIDD, J.; BESSANT, J.; PAVITT, K. Gestão da inovação. 3 ed. Porto Alegre: Bookman, 2008.

\section{Dados dos autores:}

Nome completo: Silvia Mara Bortoloto Damasceno

Filiação institucional: Universidade Tecnológica Federal do Paraná - UTFPR 
Departamento: Programa de Pós-Graduação em Engenharia de Produção

Função ou cargo ocupado: Mestranda

Endereço completo para correspondência (bairro, cidade, estado, país e CEP): Av. Espírito Santo, 420, zona 01, Cianorte, Paraná, Brasil, CEP: 87.200-000

Telefones para contato: 44-9905-7766

e-mail:smbdamasceno@uem.br

Nome completo: Danielly Silva de Aquino

Filiação institucional: Universidade Tecnológica Federal do Paraná - UTFPR

Departamento: Programa de Pós-Graduação em Engenharia de Produção

Função ou cargo ocupado: Programa de Pós-Graduação em Engenharia de Produção

Endereço completo para correspondência (bairro, cidade, estado, país e CEP): Rua Carlos Gomes, 191, centro, Goioerê, Paraná, Brasil, CEP: 87.360-000

Telefones para contato: 44-9981-8757

e-mail:dsaquino@uem.br

Nome completo: Patrício Henrique Vasconcelos

Filiação institucional: Universidade Tecnológica Federal do Paraná - UTFPR

Departamento: Programa de Pós-Graduação em Engenharia de Produção

Função ou cargo ocupado: Mestrando

Endereço completo para correspondência (bairro, cidade, estado, país e CEP): Av. Monteiro

Lobato, 1259, apto 54, Ponta Grossa, Paraná, Brasil, CEP: 84.015-480

Telefones para contato: 42-9951-3601

e-mail:adm.patricio@yahoo.com.br

Nome completo: Dálcio Roberto dos Reis

Filiação institucional: Universidade Tecnológica Federal do Paraná - UTFPR

Departamento: Programa de Pós-Graduação em Engenharia de Produção

Função ou cargo ocupado: Docente

Endereço completo para correspondência (bairro, cidade, estado, país e CEP): Av. Monteiro

Lobato, s/n, Ponta Grossa, Paraná, Brasil, CEP: 84.015-480

e-mail:dalcio@utfpr.edu.br

Nome completo: Alexandre Dias Barcelos

Filiação institucional: Faculdade Tecnológica Paranaense - FATEP

Departamento: Teologia/Filosofia

Função ou cargo ocupado: Docente 
Endereço completo para correspondência (bairro, cidade, estado, país e CEP): Av. Souza naves, 343, centro, Cianorte, Paraná, Brasil, CEP: 87.200-000

Telefones para contato: 44-9977-0787

e-mail:7barcelos@gmail.com

Enviado em:12/12/2010

Aprovado em: 25/09/2011 